\section{Erroneous connection of the fresh gas flow to the anesthesia circuit}

To the Editor:

We would like to bring to your attention a critical incident which occurred with the 1998 model Datex AS/3 anesthetic delivery unit (Datex-Ohmeda Inc., Madison, WI, USA) in the obstetrical suite at our hospital. During an emergency Cesarean section for severe fetal distress with a possible abruptio placentae and a failed epidural anesthetic, a general anesthetic was commenced after ascertaining that the oxygen flow was at $6 \mathrm{~L} \cdot \mathrm{min}^{-1}$ and positive pressure could be obtained in the patient circuit using a machine which had been checked previously.

After induction of anesthesia the patient became immediately cyanotic and ventilation was not possible in the manual mode. Measures taken included removal of the endotracheal tube, mask ventilation with oxygen supplied from a separate flowmeter, reintubation and ventilation with the manual resuscitation bag with return of $100 \%$ oxygen saturation. Anesthesia was main-

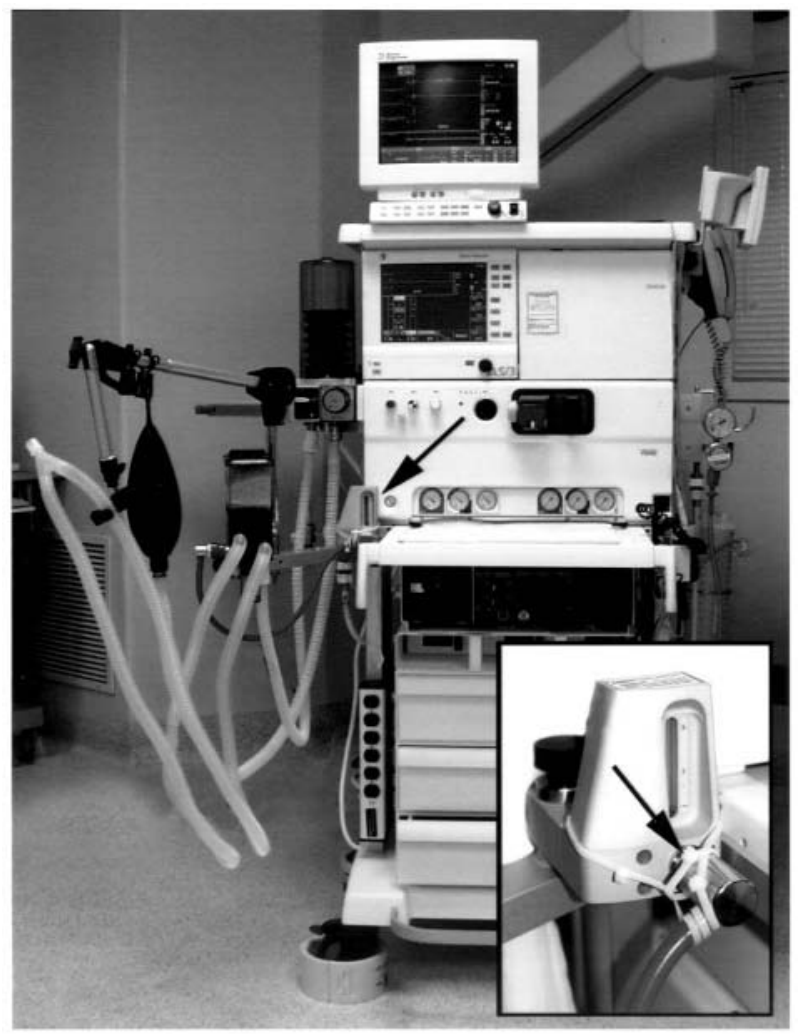

FIGURE Depicts the securance of the fresh gas flow hose to the fresh gas outlet of the Datex gas machine to prevent the erroneous connection that was present in this obstetrical case. tained with intermittent injections of iv propofol. At this point it was noted that the fresh gas flow tubing was disconnected and the ventilator hose was connected to the fresh gas flow outlet on the anesthetic machine. The hoses were then reconnected correctly and the anesthetic was conducted in the usual manner with a good outcome for the mother and infant.

Subsequent simulation of the wrong connections demonstrated that the breathing bag would pressurize but there was no flow of oxygen in the patient circuit and the breathing bag did not deflate. Following this event the fresh gas flow hose and outlet have been fastened securely as shown in the Figure. This procedure has been carried out on every AS/3 machine in our institution.

Much has been written about the anesthetic machine and patient safety ${ }^{1,2}$ from anesthetic machine malfunction $^{3}$ and faulty connections ${ }^{4}$ to human error. ${ }^{5}$ Yet, this continues to be a problem. This event demonstrates the importance in an emergency situation of detecting fresh gas flow from the circuit itself prior to induction of anesthesia in every make of anesthetic machine.

John S. McLean MD

Patricia Houston MD MED

Robert Dumais MD

Toronto, Ontario

\section{References}

1 Westhorpe $R$. The anaesthetic machine and patient safety. Ann Acad Med Singapore 1994; 23: 592-7.

2 Sloan IA. The new anesthesia machines (Editorial). Can J Anesth 2000; 47: 201-4.

3 Chang JL, Larson CE, Bedger RC, Bleyaert AL. An unusual malfunction of an anesthetic machine (Letter). Anesthesiology 1980; 52: 446-7.

4 Dolan PF. Connections from anesthetic machine to circle system unsatisfactory (Letter). Anesthesiology 1979; $51: 277$.

5 Gaba DM. Human error in anesthetic mishaps. Int Anesthesiol Clin 1989; 27: 137-47.

\section{Dopamine for renal protection}

To the Editor:

We have read the comments of Bracco and Parlow ${ }^{1}$ on the meta-analysis of Kellum and Decker ${ }^{2}$ with interest. They have reviewed a seemingly important metaanalysis and provided interesting additional viewpoints on an important topic. Unfortunately, the paper by Kellum and Decker is a problematic basis for such 